\title{
Plasma lecithin-cholesterol acyltransferase deficiency in a child with terminal pulmonary hyaline membrane disease
}

\author{
R. A. HARKNESS, J. A. B. DARLING, A. D. BAIN, and J. SYME \\ From the Departments of Paediatric Biochemistry and Paediatric Pathology, Royal Hospital for Sick Children; and \\ Medical Paediatric Unit, Western General Hospital, Edinburgh
}

Harkness, R. A., Darling, J. A. B., Bain, A. D., and Syme, J. (1973). Archives of Disease in Childhood, 48, 906. Plasma lecithin-cholesterol acyltransferase deficiency in a child with terminal pulmonary hyaline membrane disease. The clinical and biochemical findings are described in a term infant who showed oedema, then severe diarrhoea, and finally pulmonary hyaline membrane disease. $\mathrm{He}$ died at the age of 38 days. Investigation of necropsy material showed a deficiency of the plasma enzyme lecithin-cholesterol acyltransferase (LCAT), which catalyses the transfer of fatty acids from lecithin to cholesterol to form cholesterol esters. Other evidence obtained before and at necropsy was consistent with this diagnosis, though this rare isolated enzyme deficiency has so far generally been associated with disease in adults. The possible relevance of the above findings to classical pulmonary hyaline membrane disease which occurs in premature infants is discussed, since this condition is also associated with changes in phospholipid metabolism.

The present findings provide further support for the hypothesis that LCAT is important in the maintenance of membrane function.

Hyaline membrane disease is an important cause of illness and sometimes death in premature infants. Some of the causes of the syndrome are related to phospholipid metabolism; low lecithin levels in amniotic fluid are now used as an indication of the possible development of hyaline membrane disease (Gluck et al., 1971; Nelson, 1972; Bhagwanani, Fahmy, and Turnbull, 1972; Whitfield et al., 1972). Further understanding of the pathogenesis of the changes found in hyaline membrane disease may be provided by our finding of a probable deficiency of the enzyme lecithin-cholesterol acyltransferase (LCAT) in an infant with severe diarrhoea and atypical hyaline membrane disease. This enzyme is involved in phospholipid metabolism catalysing the transfer of fatty acids from lecithin to cholesterol, and is also believed to be associated with the maintenance of membrane function (Glomset, 1968).

\section{Case report}

The patient was a boy; the firstborn of healthy young British parents. The vertex delivery was spontaneous and the infant was in satisfactory condition at birth,

Received 15 May 1973. though light with a birthweight of $2.37 \mathrm{~kg}$ at a gestational age of 41 weeks. Physical examination, however, showed no evidence of congenital malformation or features suggesting placental inadequacy. Initial progress in the newborn period was satisfactory and the infant fed well on a dried milk preparation (Ostermilk No. 2) until oedema of both feet and ankles was noted at the age of 5 days. A persistent normochromic normocytic anaemia was noted; the haemoglobin concentration falling to $6.7 \mathrm{~g} / 100 \mathrm{ml}$ with only $0.6 \%$ reticulocytes. Burr cells were seen on the blood films. Other investigations showed no evidence of cardiovascular or renal abnormality and serum electrolyte and protein concentrations were normal; chromosome analysis and a Guthrie test gave normal results. There was no report of previous metabolic disease in the family.

At the age of 10 days the infant began to lose weight, and 2 days later developed profuse diarrhoea with profound metabolic acidosis and the rapid appearance of clinical features of severe dehydration. The stools were watery, green in colour, and $p \mathrm{H}$ was $6 \cdot 0$, though on two occasions stool $p \mathrm{H}$ fell to $5 \cdot 2$. On one occasion, when areterial blood $p \mathrm{H}$ was $7 \cdot 2$, stool $p \mathrm{H}$ was 6.7 and urine pH 5.0. Traces of reducing substances were noted on only two stool specimens. Repeated cultures of stool and culture of blood, urine, nose, throat, and skin swabs yielded no bacterial pathogens and, subsequently, failure to culture pathogenic viruses from stool and blood was 
reported. The stool at no time contained occult blood and repeated physical examination of the abdomen showed only occasional minimal distension.

Over the next 27 days severe diarrhoea persisted. On the basis of a tentative diagnosis of intestinal lactase deficiency or cow's milk allergy, feeds free of cow's milk and of lactose were given, without improvement in symptoms or relief of profound metabolic acidosis. Feeding with solutions of fructose and of medium chain triglycerides proved equally unsuccessful, and diarrhoea persisted even when oral feeding was reduced to $5 \%$ dextrose or fructose solution.

Throughout the illness it was frequently necessary to correct the infant's dehydration and metabolic acidosis by parenteral solutions given over short periods. However, on the 33rd day of life it was decided to abandon attempts to feed the infant by mouth. A catheter was inserted into the superior vena cava and thereafter he received a solution of amino acids (Vamin) and sorbitol, with added potassium and calcium solutions adjusted to give an intake of water, nitrogen, total calories, and electrolytes calculated to be adequate. The rate of infusion was kept constant with a microinfusion pump. This regimen was continued for the next 5 days during which his diarrhoea became less severe and his metabolic acidosis less marked. On the 38th day of life, however, he developed marked respiratory distress with gross intercostal and lower sternal recession, tachypnoea, and respiratory grunting and, shortly afterwards, peripheral circulatory failure and cardiac arrest. In spite of attempts at resuscitation, the child died at the age of 38 days.

At necropsy, about 24 hours after death, the body weight was $2.37 \mathrm{~kg}$. In the thorax the most striking feature was the bulky, solid, relatively airless appearance of the lungs, consistent with hyaline membrane disease. The heart was of appropriate size and developmentally normal. In the abdomen the liver and spleen showed slight enlargement but there was no evidence of enteritis or colitis.

On microscopy, the most significant histological finding was in the lungs which showed the terminal air spaces to be lined by thick acidophil amorphous material consistent with the appearance of hyaline membrane disease (Fig. 1.). There was no evidence of inflammatory exudate, nor was there haemorrhage. The liver showed fatty change. No histological abnormalities were found in intestine, pancreas, adrenal, spleen, heart, or kidney. In addition, the brain showed that the myelin was probably normal and there was no evidence of spongy degeneration.

\section{Methods}

Plasma lipids were extracted by a method derived from that of Karlsson and his colleagues (Karlsson, Norrby, and Samuelsson, 1967). The phospholipids were separated on thin layers of silica gel $G$ by the solvent systems described by Farquhar (1962). For separation of cholesterol, cholesterol esters, triglycerides, and free fatty acids the solvent systems described by Kellum (1967) were used. The lipids were detected by $8 \% \mathrm{w} / \mathrm{v}$

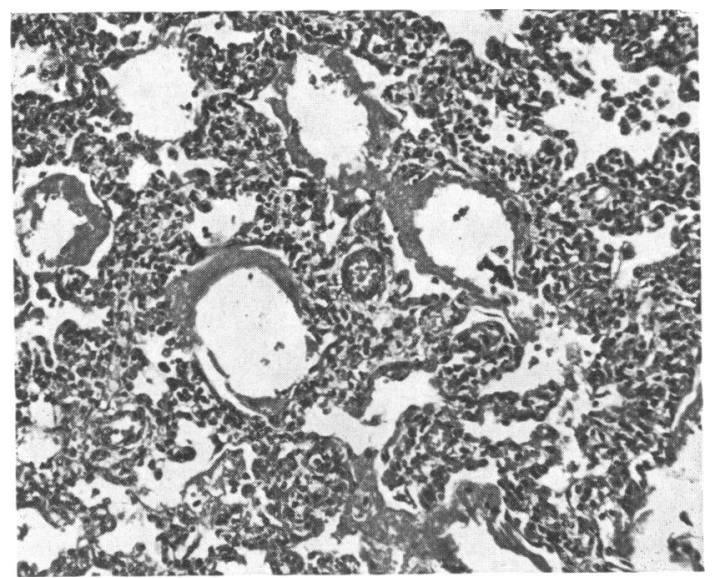

FIG. 1.-Lung showing thick well-developed hyaline membrane. (Haematoxylin and eosin. $\times 110$.)

phosphomolybdic acid in methanol. Plasma LCAT activity was estimated initially by following the removal of one substrate, the reduction of free cholesterol, after incubation of the plasma at $37^{\circ} \mathrm{C}$. Free cholesterol was estimated after digitonin precipitation by the colorimetric method of Searcy and Bergquist (1960). In view of the low LCAT activity in necropsy plasma samples, it was necessary to use a radiochemical method. The method employed was that of Norum and Gjone (1967) who modified the method of Glomset and Wright (1964). Cholesterol-7 $\alpha{ }^{3} \mathrm{H}$ with human albumin was prepared as lipid-protein substrate as described by Porte and Havel (1961). After incubation and the extraction of the lipids, the reaction products, the cholesterol esters, were separated from the substrate cholesterol by thin layer chromatography on silica gel $G$ using the solvent systems of Kellum (1967). Blank estimations were made with heat inactivated plasma. All estimates of enzyme activity were performed in duplicate on at least 2 samples. Radioactivity was estimated, after elution of the lipids from the silica gel by liquid scintillation with estimates of counting efficiency derived from added internal standard. A total of at least 2000 counts was recorded on each sample.

\section{Results}

Initial investigations of amino acid and carbohydrate metabolism were difficult to make due to the presence of large amounts of amino acids and sugars derived from parenteral feeding. However, by a series of chromatographic, microchemical, and, in the case of amino acids, high voltage electrophoretic methods, no abnormal accumulation of amino acids or carbohydrates in blood or urine other than those in the infusion was shown. Extracts of liver and kidney were examined for amino acid content and a similar pattern found to that in blood. 
In view of the pulmonary changes of hyaline membrane disease, special attention was paid to chromatographic separations of plasma and red blood cell lipids. These showed no detectable levels of lysolecithin in plasma (Fig. 2). This was

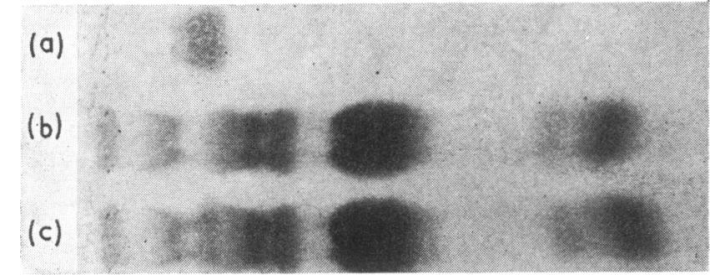

FIG. 2.-The absence of lysolecithin in the thin layer chromatogram of serum phospholipids. (a) Lysolecithin standard, (b) lipid extract from the serum of the child, (c) the same lipid extract with lysolecithin added.

confirmed, and from the limits of detection of the method used it was calculated that the lysolecithin levels were less than $0.8 \mathrm{mg} / 100 \mathrm{ml}$. Though necropsy samples contain less lysolecithin than samples from living matter, this result was abnormal. Using the same method, lysolecithin was definitely detected in 15 of 16 consecutive samples of blood from necropsy examinations; in only one case was there doubt about its presence (Table). Other plasma lipids in the affected infant were not so obviously abnormal. Total cholesterol was 95 $\mathrm{mg} / 100 \mathrm{ml}$ and free cholesterol $47 \mathrm{mg} / 100 \mathrm{ml}$; about $50 \%$, instead of the usual 60 to $80 \%$, of the cholesterol was esterified.

The fatty acid composition of the cholesterol ester, triglyceride, and phospholipid fractions from the necropsy samples of the affected infant and a control infant were determined (Drs. Moore and Noble, Hannah Dairy Research Institute, Ayr). Some rise in the 18:0 and 18:1 fatty acids in the cholesterol ester fraction was found, which was in agreement with findings in other cases of LCAT deficiency (Norum, Glomset, and Gjone, 1972). The other notable feature in the affected infant was lower levels of 18:2 and 20:4 fatty acids in the phospholipid fraction. The 16:0 fatty acids in all 3 lipid fractions were similiar in the samples from the affected infant and from the control infant. If the substrate specificity of human LCAT is similar to that in cows (Noble, O'Kelly, and Moore, 1972), the reduction of the 18:2 fatty acids in the phospholipids might cause some reduction in LCAT activity.

The absence of detectable lysolecithin and the somewhat reduced amounts of cholesterol esters prompted a search for a deficiency of LCAT
TABLE

Lysolecithin and radiochemical estimates of LCAT activity in necropsy serum samples

\begin{tabular}{|c|c|c|c|}
\hline $\begin{array}{l}\text { Necropsy } \\
\text { sample }\end{array}$ & $\begin{array}{l}\text { Approximate } \\
\text { time interval } \\
\text { between death } \\
\text { and sample } \\
\text { collection (hr) }\end{array}$ & $\begin{array}{c}\text { Activity in } \\
\text { cholesterol ester } \\
\text { fraction above } \\
\text { blank } \\
\text { (counts/min) }\end{array}$ & $\begin{array}{c}\text { Lysolecithin } \\
\text { detection } \\
\text { on TLC }\end{array}$ \\
\hline $\begin{array}{r}1 \\
2 \\
3 \\
4 \\
5 \\
6 \\
7 \\
8 \\
9 \\
10 \\
11 \\
12 \\
13 \\
14 \\
15 \\
16 \\
17 \\
18 \\
19 \\
20\end{array}$ & $\begin{array}{c}56 \\
60 \\
29 \\
46 \\
24 \\
48 \\
66 \\
48 \\
48 \\
72 \\
48 \\
48 \\
\text { Not known } \\
72 \\
48 \\
24 \\
28 \\
108 \\
61 \\
36\end{array}$ & $\begin{array}{r}41 \\
8 \\
254 \\
192 \\
42 \\
10 \\
44 \\
356 \\
278 \\
0 \\
187 \\
83 \\
289 \\
616 \\
342 \\
475 \\
87 \\
74 \\
33 \\
90\end{array}$ & $\begin{array}{r}+ \\
++ \\
++ \\
++ \\
++ \\
++ \\
? \\
++ \\
++ \\
++ \\
++ \\
++ \\
\star \\
++ \\
+ \\
\star \\
++ \\
\star \\
\star \\
+\end{array}$ \\
\hline
\end{tabular}

LCAT, lecithin-cholesterol acyltransferase; TLC, thin layer chromotography.,,++++++ , indicate approximate quantities of lysolecithin detected.

$\star$ Insufficient sample for lipid investigation.

activity in plasma (Norum et al., 1972). Initial investigations showed that free cholesterol in plasma from 8 children was reduced by incubation at $37^{\circ} \mathrm{C}$, whereas the level of free cholesterol in the affected child was not changed. However, LCAT activity in all necropsy plasma samples was low, about $10 \%$ of the normal activity (Table). LCAT activity of plasma from 16 live children, estimated by the radiochemical method, gave similar results to those of Norum and Gjone (1967); therefore, a radiochemical method was used in all subsequent investigations. LCAT activity was not found in the affected infant's plasma on 3 occasions using duplicate estimates at each attempt. In contrast, LCAT activity was shown in 19 of 20 consecutive samples from separate necropsy examinations (Table). It should be noted that the sample in which LCAT activity was not shown contained readily detectable amounts of lysolecithin, as did samples 2 and 6 which showed low LCAT activity.

On the basis of the above evidence, it seems justifiable to suggest that the affected infant had a deficiency of LCAT activity, despite the problems of having to make the diagnosis on necropsy material after treatment.

The reasons for the low levels of LCAT activity in the necropsy material are not clear. The LCAT activities found after mixing plasma from necropsy 
samples with that from live individuals showed more activity than expected from simple addition, suggesting that substrate deficiency rather than the development of an inhibitor was the basis of at least part of the low activity in necropsy plasma (Noble et al., 1972). However, the work of Fielding, Shore, and Fielding (1972) suggests that this change is not due to simple alterations in the lipids involved in this reaction. There was a slight inhibitory effect on LCAT activity of the amino acid infusion used at approximately the maximum concentration used in vivo. In the 4 samples studied, only a $10 \%$ reduction in activity was found.

In both parents plasma LCAT activity, lipids, and lipoproteins were within normal limits. These findings are consistent with the diagnosis of LCAT deficiency in the child (Norum et al., 1972).

\section{Discussion}

The difficulties of defining a deficiency of LCAT in necropsy plasma must be emphasized, especially since the occurrence of severe disease and some clinical findings in this case have not previously been associated with the small numbers of cases of LCAT deficiency so far described. A mild normochromic, normocytic anaemia has, however, been a feature of the described cases (Norum et al., 1972), as it was of the affected infant. The oedema of both feet, noted in this case from the age of 5 days, may have been due to altered capillary permeability. Proteinuria has previously been found in LCAT deficiency as early as 3 to 4 years of age; though no proteinuria was noted on testing the child's urine at the fifth day, it was detected later. The severe diarrhoea apparent from 10 days of age may have been linked to the high de novo biosynthesis of phospholipids and cellular turnover in the intestine (Dawson, 1966). There was no evidence of enteritis or colitis at necropsy, but there was evidence that the pulmonary changes were not secondary to left-sided heart failure. It must be emphasized that it is unlikely that hyaline membrane disease was present until the last few days of life in the child described above, and the clinical course of this disease was different from that of typical pulmonary hyaline membrane disease.

The relation between the functional maturity of the pulmonary alveolar membranes and their lecithin content is widely accepted and clinically useful (Gluck et al., 1971; Nelson, 1972; Bhagwanani et al., 1972; Whitfield et al., 1972). Changes in pulmonary phospholipid synthesis and storage with development have been discussed by Gluck et al. (1971), and a contribution from LCAT is not excluded.
Studies of plasma LCAT in the rat have shown a sharp increase at birth followed by a gradual fall in activity to a minimum at the 12th day, which is followed by an increase to the 30th day of age (Curnow and Crawford, 1972). In man LCAT activity in umbilical cord plasma is similar to activity in the adult when allowance is made for the lower endogenous substrate concentrations in umbilical cord plasma (Lacko, Rutenberg, and Soloff, 1972). LCAT is clearly present at birth in both species but this activity may be derived from maternal sources. Transfer of immunoglobulins from mother to fetus is known to occur (Cochran, 1972), and contamination of umbilical cord blood samples by maternal blood is difficult to avoid (Cohen and Zuelzer, 1965). It is therefore possible that plasma LCAT is initially derived from the mother and the newborn begins to synthesize this enzyme only some time after birth. The above evidence does not, therefore, exclude a delay in the synthesis of LCAT as a possible basis for some cases of hyaline membrane disease occurring in premature infants.

As to the connexion between the deficiency of LCAT and hyaline membrane disease in our infant, at least two interpretations are possible. Either the absence of LCAT may have caused indirectly a lower rate of synthesis of dipalmitoyl lecithin in the lung due to a derangement in the fatty acid residues available for the formation of pulmonary surfactant, or the cell membranes of the alveolar epithelium were so altered by the deficiency of LCAT that they were unable to retain any surfactant formed within the cuboidal alveolar epithelial cells.

It appears essential to try to confirm our findings in view of the difficulty of establishing the diagnosis of LCAT deficiency on necropsy material. The diagnosis was especially difficult to confirm because LCAT activity is not found in cells (Glomset and Kaplan, 1965), though it is probably produced in the liver (Norum et al., 1972). It was not, therefore, possible to use tissue or tissue culture in these studies. We hope that our results will stimulate further studies in view of the possible importance of our findings in indicating one of the many factors responsible for the maintenance of pulmonary and intestinal function.

\section{REFERENCES}

Bhagwanani, S. G., Fahmy, D., and Turnbull, A. C. (1972) Prediction of neonatal respiratory distress by estimation of amniotic-fluid lecithin. Lancet, 1, 159.

Cochran, T. E. (1972). Fetal and maternal immunoglobulin concentrations at delivery and post partum. Fournal of Obstetrics and Gynaecology of the British Commonwealth, 79, 238.

Cohen, F., and Zuelzer, W. W. (1965). The transplacental passage of maternal erythrocytes into the fetus. American fournal of Obstetrics and Gynecology, 93, 566. 
Curnow, D. H., and Crawford, I. G. (1972). Development of plasma lecithin-cholesterol acyltransferase in the perinatal rat. (Abst.) Scandanavian Fournal of Clinical and Laboratory Investigation, 29, Suppl. 126, 3.12.

Dawson, R. M. C. (1966). The metabolism of animal phospholipids and their turnover in cell membranes. In Essays in Biochemistry, Vol. 2, p. 69 . Ed. by P. N. Campbell and G. D. Greville. Academic Press, London.

Farquhar, J. W. (1962). Human erythrocyte phosphoglycerides. 1. Quantification of plasmalogens, fatty acids and fatty aldehydes. Biochimica et Biophysica Acta, 60, 80.

Fielding, C. J., Shore, V. G., and Fielding, P. E. (1972). Lecithincholesterol acyltransferase: effects of substrate composition upon enzyme activity. Biochimica et Biophysica Acta, 270, 513.

Glomset, J. A. (1968). The plasma lecithin-cholesterol acyltransferase reaction. Fournal of Lipid Research, 8, 155.

Glomset, J. A., and Kaplan, D. M. (1965). The distribution of plasma fatty acid transferase-like activity in rat tissues. Biochimica et Biophysica Acta, 98, 41.

Glomset, J. A., and Wright, J. L. (1964). Some properties of a cholesterol esterifying enzyme in human plasma. Biochimica et Biophysica Acta, 89, 266.

Gluck, L., Kulovich, M. V., Borer, R. C., Brenner, P. H., Anderson, G. G., and Spellacy, W. N. (1971). Diagnosis of the respiratory distress syndrome by amniocentesis. American fournal of Obstetrics and Gynecology, 109, 440.

Karlsson, K. A., Norrby, A., and Samuelsson, B. (1967). Use of thin-layer chromatography for the preliminary diagnosis of Refsum's disease (Heredopathia atactica polyneuritiformis). Biochimica et Biophysica Acta, 144, 162.

Kellum, R. E. (1967). Human sebaceous gland lipids. Analysis by thin-layer chromatography. Archives of Dermatology, 95, 218.
Lacko, A. G., Rutenberg, H. L.., and Soloff, L. A. (1972). On the rate of cholesterol esterification in cord blood serum. Lipids, 7, 426.

Nelson, G. H. (1972). Relationship between amniotic fluid lecithin concentration and respiratory distress syndrome. American Fournal of Obstetrics and Gynecology, 112, 827.

Noble, R. C., O'Kelly, J. C., and Moore, J. H. (1972). Observations on the lecithin-cholesterol acyltransferase system in bovine plasma. Biochimica et Biophysica Acta, 270, 519.

Norum, K. R., and Gjone, E. (1967). Familial plasma lecithincholesterol acyltransferase deficiency. Scandanavian fournal of Clinical and Laboratory Investigation, 20, 231.

Norum, K. R. Glomset, J. A., and Gjone, E. (1972). Familial plasma lecithin-cholesterol acyltransferase deficiency. In The Metabolic Basis of Inherited Disease, 3rd ed., p. 531. Ed. by J. B. Stanbury, J. B. Wyngaarden, and D. S. Fredrickson. McGraw-Hill, London and New York.

Porte, D., and Havel, R. J. (1961). The use of cholesterol-4-14C labelled lipoproteins as a tracer for plasma cholesterol in the dog. Fournal of Lipid Research, 2, 357.

Searcy, R. L., and Bergquist, L. M. (1960). A new color reaction for the quantification of serum cholesterol. Clinica Chimica Acta, 5, 192.

Whitfield, C. R., Chan, W. H., Sproule, W. B., and Stewart, A. D. (1972). Amniotic fluid lecithin: sphingomyelin ratio and fetal lung development. British Medical fournal, 2, 85.

Correspondence to Dr. R. A. Harkness, Department of Paediatric Biochemistry, Royal Hospital for Sick Children, 1 Rillbank Crescent, Edinburgh EH9 1LJ. 